\title{
Mal-estar no Trabalho: Análise da Cultura Organizacional de um Contexto Bancário Brasileiro
}

\author{
Mário César Ferreira ${ }^{1}$ \\ Juliana Seidl \\ Universidade de Brasília
}

\begin{abstract}
RESUMO - O objetivo deste estudo foi examinar as variáveis que compõem o mal-estar no trabalho correlacionando-as com aspectos da cultura/cultura organizacional e com uma perspectiva taxonômica dos fatores constituintes de um contexto de trabalho. Tais variáveis foram obtidas por meio da análise dos resultados de uma pesquisa empírica em um contexto organizacional bancário do serviço público brasileiro. Os participantes foram 1.164 bancários, sendo 78\% do sexo masculino. Para o tratamento de dados, foi utilizado um software de análise quantitativa de dados textuais: Alceste. Os resultados evidenciaram cinco núcleos temáticos e dois eixos estruturadores do discurso dos bancários que revelaram traços da cultura organizacional. Esses elementos foram correlacionados com as noções de Bem-Estar no Trabalho (BET) e de Contexto de Produção de Bens e Serviços (CPBS) e serviram de base para delinear os principais focos do mal-estar no trabalho.
\end{abstract}

Palavras-chave: cultura organizacional; mal-estar no trabalho; serviço público; trabalho bancário.

\section{Work Malaise: Analysis of the Organizational Culture of a Brazilian Banking Context}

\begin{abstract}
The goal of the present study was to examine the variables that compose work malaise by correlating them with aspects of the culture/organizational culture and with a taxonomic perspective of the factors that constitute a work context. Those variables were obtained after the analysis of an empirical research conducted at a Brazilian public banking institution. The participants were 1,164 bank employees (78\% male). For the data treatment, a software for quantitative analysis of textual data was used: Alceste. The results showed five theme cores and two axes that oriented the banking employees' speech, which revealed traits of the organizational culture. These elements were correlated to the concepts of well-being, and the goods and services production context that served as the basis to outline the main focuses of work malaise.
\end{abstract}

Keywords: organizational culture; work malaise; public sector; bank work.

Bem-estar e mal-estar são fenômenos que coabitam o mundo do trabalho. Do ponto de vista empírico, inúmeros estudos mostram uma diversidade de indicadores nas duas temáticas. Entretanto, no que concerne ao campo conceitual, em particular no que tange às definições, o conceito de mal-estar no trabalho é largamente residual na literatura científica. A temática do presente artigo centra-se na análise dos resultados de uma pesquisa empírica sobre mal-estar no trabalho em um contexto organizacional bancário no serviço público brasileiro.

O objetivo deste trabalho consistiu em examinar as representações dos participantes da pesquisa (bancários) concernentes às variáveis relacionadas com o mal-estar no trabalho, correlacionando-as com aspectos da cultura/cultura organizacional e com uma perspectiva taxonômica de fatores constituintes de um contexto de trabalho. Um quadro teórico de referência, articulando as diferentes dimensões analíticas, é proposto para interpretar os resultados obtidos em diálogo com outros achados na literatura científica.

1 Endereço para correspondência: Instituto de Psicologia, Universidade de Brasília, Campus Darcy Ribeiro. Brasília, DF. CEP 70910-900. Tel.: (61) 33072668 Ramal: 224.E-mail: mcesar@unb.br.

\section{Quadro Teórico de Referência}

Duas dimensões conceituais serviram de suporte teórico para a interpretação dos resultados obtidos na pesquisa. Com base na temática do artigo, tais dimensões são apresentadas a seguir, explicitando os enfoques adotados.

\section{Cultura e cultura organizacional}

Cultura é uma dessas noções nômades que vagueia pela literatura científica. Dependendo de onde esteja, sua acepção assume diferentes feições. Uma rápida revisão da literatura permite construir o cenário do sentido de cultura no qual se inscreve a noção de cultura organizacional propriamente dita. O que diz o dicionário eletrônico Houaiss (2002) constitui um pertinente ponto de partida.

O Houaiss (2002) apresenta oito significados para o termo cultura. Globalmente, há dois sentidos interessantes: (a) no primeiro, de natureza etimológica, o verbete expressa "ação, processo ou efeito de cultivar a terra; lavra, cultivo"; a derivação por metonímia assume cultura como "produto de tal cultivo, plantação, criação ou desenvolvimento com cuidados especiais"; (b) o segundo, mais recente, enfatiza a dimensão social, ou seja, "um conjunto de padrões de comportamento, 
crenças, conhecimentos, costumes que distinguem um grupo social”. Tais sentidos manifestam pertinência para a temática do presente artigo na medida em que se reportam aos modos de fazer (trabalho) - primeiro sentido - e aos modos, lato sensu, de conduta e de pensar - segundo sentido.

No contexto científico, a cultura tem sido objeto de estudo, sobretudo, da antropologia e da sociologia. Nesses territórios científicos, o termo assume sentidos diversos, cobrindo uma diversidade de acepções: comunicação, cooperação social, simbolização, interações sociais, produção/transmissão de conhecimentos, criação intelectual, códigos, padrões de condutas, modos de comportamentos, crenças, valores espirituais, atividade simbólica/material. Regra geral, tais dimensões cumprem um papel mediador da interação entre os humanos e o meio físico e social e, ao mesmo tempo, forjador da história da civilização. Alguns dos enfoques dominantes da abordagem de cultura em diferentes campos disciplinares são salientados por Ferreira (2004):

Em antropologia cultural, o pressuposto que tem orientado inúmeros estudos etnográficos consiste na indissociabilidade entre simbolismo e prática social, ou seja, inter-relação simbiótica entre o agir (ação) e sua significação (representação) (Levi-Strauss, Goodenough). Paradigma que pode ser também formulado em termos de pensamento-ação e que está igualmente presente em outras disciplinas como a psicologia (Piaget, Vigostsky, Leontiev) e a própria Ergonomia da Atividade (Ombredane, Faverge, Weill-Fassina, Rabardel). ... Na perspectiva antropológica, os padrões culturais identificados foram analisados com base nas atividades dos sujeitos, sobretudo, nas distintas formas de mediação atuando nas esferas do significado e do fazer coletivo. Já no campo da sociologia, os trabalhos de Goffman, Berger e Luckmann são referências que se orientam pelo pressuposto de que o real é uma construção social. Nessa perspectiva, o processo de construção do simbólico, a produção de signos lingüísticos e o compartilhamento social de senso comum se constituem em elementos que dão visibilidade à dimensão cultural. (p. 185)

Em uma acepção mais pontual, a definição elaborada por Motta (1997) fornece bases conceituais para uma visão mais totalizante do que vem a ser cultura. Escreveu o autor (grifos nossos):

Os seres humanos vivem em um universo de significações. Eles decodificam sem cessar, não apenas as palavras de seus semelhantes, mas também suas expressões, suas posturas, suas ações dos mais variados tipos, sempre lhes atribuindo um sentido. Ocorre da mesma forma com os sentidos que vão assumir suas próprias ações. Essa significação está muito longe de ser universal e está sempre relacionada a uma espécie de linguagem particular. Antes de mais nada, a cultura é linguagem, é código. Ela fornece um referencial que permite aos atores dar um sentido ao mundo em que vivem e as suas próprias ações. Ela designa, classifica, liga, coloca em ordem. Define os princípios de classificação que permitem ordenar a sociedade em grupos distintos, desde que dão sentido às dificuldades da existência, apresentando-as como elementos de uma ordem ou como fruto de sua perturbação. (pp. 26-27)
Todavia, os sentidos que a cultura assume nos ambientes de trabalho fornecem e consolidam fundamentos teóricos que serviram de suporte para a condução da pesquisa que dá origem ao presente artigo.

É a partir da década de 80 que emerge a “cultura organizacional" como objeto específico de produção de conhecimentos científicos (Hofstede, 1980; Motta \& Caldas, 1997; Spink, 1997), tomando impulso importante na década de 90 (Fleury, Shinyashiki \& Stevenato, 1997). Atualmente, a abordagem de Schein (1989) aparece como “campeã” de citações na literatura. Esse autor define cultura organizacional como um conjunto de pressupostos básicos eficazes, inventados, descobertos ou elaborados por um grupo que resultam do aprendizado ao lidar com problemas de adaptação externa e/ ou de integração interna. O caráter eficaz de tais pressupostos se constitui, segundo o autor, no modo principal por meio do qual se opera a sua legitimação e sua transmissão aos novos membros do grupo como modelo correto de perceber, pensar e sentir em relação a tais problemas (Bertero, 1996; Fleury, 1996a). Apesar do uso recorrente da definição proposta por Schein, constata-se que a definição de cultura organizacional ainda está longe de ser um objeto de consenso na literatura (ver, por exemplo, as definições propostas por Fleury, 1996b; Garay, 2000).

O conceito de cultura organizacional adotado neste trabalho é o proposto por Freitas (1997). A autora define cultura organizacional da seguinte forma (grifos nossos):

“... um conjunto de representações imaginárias sociais ..., construídas e reconstruídas nas relações cotidianas dentro da organização, que são expressas em termos de valores, normas, significados e interpretações, visando a um sentido de direção e unidade, e colocando a organização como fonte de identidade e de reconhecimento para os seus membros”. (p. 294-295)

O enfoque de Freitas (1997) fornece, portanto, um primeiro suporte conceitual para a análise das verbalizações dos servidores do banco estatal sobre os possíveis indicadores de cultura organizacional.

\section{Bem-estar e mal-estar no trabalho}

Mal-estar no trabalho é um dado comum na literatura das ciências do trabalho. Aparece em inúmeros resultados de pesquisas (Diniz, 2006; Veras, 2006). Em contrapartida, o conceito propriamente dito de mal-estar no trabalho é fortemente residual em estudos e pesquisas. Assim, é com base, principalmente, na vasta produção bibliográfica sobre bem-estar que, com certos riscos interpretativos, se torna possível delinear as características do mal-estar no trabalho. A perspectiva consiste em visualizar, tal qual uma moeda, a face do bem-estar no trabalho para projetar a sua outra face, a do mal-estar no trabalho.

Para Ryan e Deci (2001), as conceituações científicas mais proeminentes da atualidade sobre bem-estar podem ser subdivididas de acordo com duas perspectivas. A primeira é a concepção denominada Bem-Estar Subjetivo (BES) que aborda o estado subjetivo de felicidade, ou seja, adota uma visão de bem-estar como prazer, o que reflete a visão filosó- 
fica hedonista. A segunda é a perspectiva de Bem-Estar Psicológico (BEP), que investiga o potencial humano. A última representa uma visão histórica eudemonista, pois se apóia na noção de que bem-estar consiste no pleno funcionamento das potencialidades de uma pessoa.

O conceito de BES foi estruturado por Diener, Scollon e Lucas (2003) por meio de um modelo hierárquico de felicidade. Para eles, o BES reflete uma avaliação geral da vida ou de domínios específicos dela e incluem duas grandes dimensões psicológicas: de um lado, a esfera afetiva que inclui os estados emocionais e sentimentos (positivos e negativos); de outro, a esfera cognitiva que diz respeitos às avaliações de satisfação com a vida em geral e, em particular, com os aspectos do trabalho. Para acessar o BES, é necessário que o próprio indivíduo faça sua auto-avaliação. Isto é, o BES não pode ser observado ou identificado por indicadores externos e/ou terceiros (Diener \& Lucas, 2000). É a pessoa quem deve avaliar suas expectativas, valores, experiências prévias e emoções.

Já a categoria conceitual de BEP é fortemente construída sobre formulações psicológicas acerca do desenvolvimento humano, dimensionadas em capacidades para enfrentar os desafios da vida. Segundo Ryff (1989), a estrutura de uma abordagem acerca do funcionamento psicológico positivo apóia-se em diversas teorias clássicas existentes em Psicologia, dentre elas: a individuação (Jung), auto-realização (Maslow), maturidade (Allport), desenvolvimento humano (Erickson). Além dessas teorias, a vertente da saúde mental também foi utilizada (Jahoda) para justificar o conceito de bem-estar como ausência de doença e fortalecer o significado de saúde psicológica.

Poucas são as definições existentes na literatura sobre o “bem-estar no trabalho”. Estudos anteriores utilizaram outros conceitos para referirem-se à noção de bem-estar no trabalho, como, por exemplo, satisfação com o trabalho (Amaral \& Siqueira, 2004), referindo-se ao próprio bem-estar, ou o burnout (Maslach, Schaufeli \& Leiter, 2001), para tratar do mal-estar. $\mathrm{O}$ enfoque adotado neste trabalho articulou os conceitos de Bem-Estar no Trabalho (BET), proposto por Gomide Júnior, Oliveira e Oliveira (2006a, 2006b), Siqueira, Padovam, Chiuzi e Covacs (2006) e Siqueira e Padovam (2008), e de Contexto de Produção de Bens e Serviços (CPBS), proposto por Ferreira e Mendes (2003).

Segundo os autores supracitados, BET é um construto psicológico multidimensional, constituído por três componentes:

- Satisfação no trabalho: estado emocional positivo ou de prazer, resultante de experiências de trabalho;

- Envolvimento com o trabalho: grau em que o desempenho de uma pessoa no trabalho afeta a sua auto-estima, representando vínculos positivos com o trabalho;

- Comprometimento organizacional afetivo: estado no qual o indivíduo se identifica com a organização particular e seus objetivos, desejando manter-se afiliado a ela com vista a realizar tais objetivos.

Por sua vez, um CBPS

“... expressa o lócus material, organizacional e social onde se opera a atividade de trabalho e as estratégias individual e co- letiva de mediação utilizadas pelos trabalhadores na interação com a realidade de trabalho. Esse contexto articula múltiplas e diversificadas variáveis, compondo uma totalidade integrada e articulada.” (Ferreira \& Mendes, 2003, p. 41)

Para os autores, o CPBS apresenta três dimensões interdependentes: (a) organização de trabalho, que é constituída pelos elementos prescritos formal e informalmente (e.g., regras, tempos, controle); (b) condições de trabalho, que caracterizam sua infra-estrutura, apoio institucional e práticas administrativas (e.g., posto de trabalho, equipamentos, suporte organizacional); e (c) relações sociais de trabalho, que expressam as interações socioprofissionais de trabalho (e.g., hierárquicas, intra e inter-grupais).

\section{Recortes analíticos com base na abordagem teórica}

À luz dos enfoques conceituais adotados, a perspectiva analítica global consistiu, portanto, em analisar os dados empíricos com base em três recortes complementares: (a) depreender em que medida os elementos constitutivos e característicos do discurso dos servidores (bancários) autorizam a delinear um perfil de cultura e cultura organizacional, neste último caso conforme definição elaborada por Freitas (1997); (b) examinar o discurso dos servidores do banco estatal com base nas noções de BET (Gomide Júnior \& cols., 2006a, 2006b; Siqueira \& cols., 2006; Siqueira \& Padovam, 2008), buscando-se identificar o "reverso da medalha", ou seja, em que medida eles autorizam um delineamento dos elementos constitutivos e característicos do mal-estar no trabalho; e (c) verificar de que modo a construção simbólica dos participantes da pesquisa - suas representações sobre o mal-estar no trabalho - se reporta às dimensões constitutivas do CPBS (Ferreira \& Mendes, 2003).

\section{Método}

A pesquisa foi realizada em um banco estatal brasileiro e cobriu todas as suas unidades administrativas, distribuídas pelas regiões do país. As especificidades metodológicas são apresentadas a seguir para instrumentalizar o leitor na compreensão dos resultados obtidos.

\section{Participantes}

Participaram da pesquisa 1.164 bancários do quadro efetivo da instituição, correspondendo a 25,5\% do total de servidores $(\mathrm{N}=4.558)$ presentes à época de sua realização. Em se tratando de uma pesquisa qualitativa com resposta à questão aberta, onde o participante tinha que responder por meio de uma plataforma eletrônica, o percentual de resposta obtido é bastante expressivo.

O perfil demográfico e profissiográfico dos participantes apresentou as seguintes características: $78,3 \%$ do sexo masculino; 91,2\% com nível de escolaridade superior completo; média de idade igual a 46 anos $(\mathrm{DP}=8,5)$; tempo médio de trabalho no banco de 17 anos ( $\mathrm{DP}=10,7)$. Com relação ao 
estado civil, a amostra de servidores foi constituída por $67,9 \%$ de pessoas casadas.

\section{Instrumento}

Um questionário foi disponibilizado na intranet do banco contendo: (a) informações preliminares (objetivos, importância da pesquisa, livre participação, confidencialidade no tratamento e divulgação dos resultados); (b) uma questão aberta "No Banco, o que eu gosto menos no meu trabalho é...” com espaço suficiente para digitação de resposta; e (c) campos para assinalar as variáveis demográficas e profissiográficas (sexo, idade, estado civil, escolaridade, tempo de trabalho no banco, tempo de trabalho no cargo atual).

\section{Procedimento}

Para aumentar o "N” de participantes na pesquisa, realizou-se uma campanha de sensibilização dos bancários por meio de mensagens eletrônicas, boletins impressos, chamadas no site da intranet e inserções em eventos específicos (e.g., video conferências). Preparou-se uma comunicação administrativa às chefias orientando sobre os cuidados necessários que poderiam facilitar a participação dos bancários, bem como, enfatizando a importância de se evitar qualquer tipo de constrangimento aos participantes da pesquisa. Para assegurar a eficácia de tal comunicação administrativa, realizou-se contato telefônico com as chefias para fornecer orientações e esclarecimentos que, porventura, se fizessem necessários.

A versão eletrônica do questionário ficou disponibilizada na intranet do banco durante o período de 1 mês. Nesse período, os participantes puderam acessá-lo e respondê-lo. Após o término do preenchimento completo do questionário, o servidor deveria acionar comando para salvar os dados.

\section{Tratamento de dados}

Os dados foram tratados com suporte do software Alceste (Analyse Lexicale par Contexte d'un Ensemble de Segments de Texte, versão 4.8), desenvolvido por Max Reinert (1990). O Alceste, uma potente ferramenta para análise automática de texto, é pertinente com o objetivo da pesquisa, pois apresenta as seguintes características: (a) identifica as informações essenciais de um texto (podendo ser usado, por exemplo, para análise de dados de entrevistas, questionários, questões abertas, obra literária); e (b) quantifica para extrair as estruturas significantes mais fortes do texto. O programa materializa o pressuposto de que as estruturas lexicais de um texto estão intimamente relacionadas por meio da distribuição das palavras em seu corpus e, ainda, que tal distribuição não se dá ao acaso.

Os dados produzidos no questionário, versão eletrônica na intranet do banco, foram formatados com base nas especificações do Alceste (e.g., não uso de hífen) visando preparar o corpus para as etapas de tratamento do programa. Assim, foi possível organizar e classificar dados textuais obtidos pelas respostas à pergunta sobre o que o servidor menos gosta no banco, por meio de uma análise hierárquica descendente. Esse tipo de análise permite a repartição do corpus textual original em unidades de contexto (classes), em função da semelhança entre as unidades de contexto elementares do texto (UCE). A descrição do conteúdo do texto, possibilitando a análise qualitativa, foi feita por meio das palavras associadas a cada classe e do contexto de ocorrência das unidades de contexto elementares (UCEs), características de cada uma das classes obtidas (Nascimento-Schulze \& Camargo, 2000). As classes obtidas, denominadas aqui de "núcleo temáticos", permitiram o acesso aos aspectos mais significativos do ponto de vista coletivo dos bancários sobre o "gostar menos no trabalho".

\section{Resultados}

A análise do relato dos respondentes à pergunta: "No Banco, o que eu gosto menos no meu trabalho é...” permitiu obter um cenário explicativo - composto por cinco núcleos temáticos - que estruturou o ponto de vista coletivo dos servidores do banco estatal. Tais núcleos temáticos apresentam aspectos quantitativos e qualitativos que constituem a base empírica para compreender a relação entre mal-estar no trabalho e cultura/cultura organizacional.

\section{Núcleos temáticos estruturadores do "gostar menos no trabalho": dimensão quantitativa}

O tratamento dos dados pelo Alceste (Reinert, 1990) gerou, na etapa quantitativa, um conjunto de resultados, possibilitando identificar (Figura 1):

- As informações essenciais (palavras) que constituem os cinco núcleos temáticos (estruturas mais significantes) que caracterizam o sentimento "gostar menos no trabalho” dos bancários, cuja análise cruzada com a etapa qualitativa possibilitou nomeá-las;

- O " $n$ ” de UCEs e respectivos percentuais de contribuição de cada núcleo temático na produção global do discurso dos respondentes;

- Os coeficientes da análise fatorial de correspondência entre os cinco núcleos temáticos identificados, revelando o grau de interdependência entre elas com base em uma escala de $0-1$. Os valores $0,6,0,4$ e 0,6 da Figura 1 expressam os graus de correspondência inter-núcleos temáticos.

Os resultados obtidos pelo tratamento quantitativo do Alceste colocam em evidência dois eixos estruturadores das representações “gostar menos no trabalho” dos bancários:

- Eixo 1 do Discurso, constituído pelos seguintes núcleos temáticos: "Ociosidade, Salário e Reciprocidade” (29,51\%); “Hostilidade e Condições Físicas” (16,67\%); "Discriminação para com os Terceirizados" (14,62\%) e "Carreira e Estilo de Chefia" (29,64\%);

- Eixo 2 do Discurso, constituído pelo núcleo temático “Trabalho Repetitivo, Controle e Divisão de Tarefas” (9,56\%). 


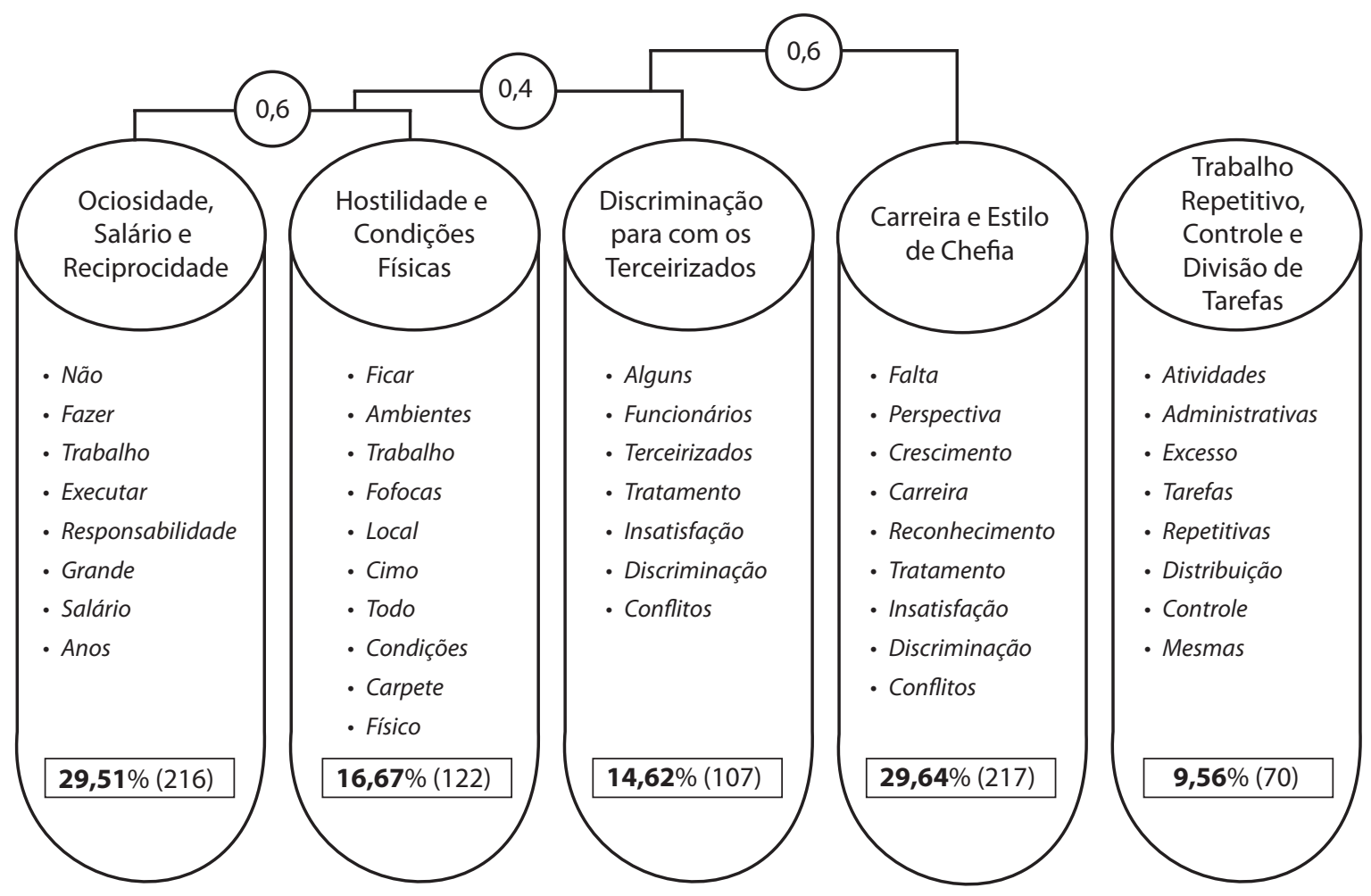

Figura 1. Núcleos temáticos estruturadores do ponto de vista coletivo dos servidores.

Tais resultados desenham um primeiro cenário empírico para análise e discussão das representações dos respondentes sobre os fatores que aparecem de modo associado ao sentimento de "gostar menos no trabalho". Todavia, os resultados qualitativos no tratamento do Alceste inserem aspectos fundamentais para a contextualização dos indicadores quantitativos constatados, produzindo uma espécie de efeito gestáltico para interpretação dos resultados.

\section{Núcleos temáticos estruturadores do "gostar menos no trabalho": dimensão qualitativa}

$\mathrm{Na}$ etapa da análise qualitativa, o Alceste identificou as UCEs que correspondem às frases mais representativas de cada núcleo temático estruturador do discurso dos respondentes. Os resultados obtidos são apresentados pelas figuras a seguir.

Em relação ao "Eixo 1 do Discurso" dos bancários sobre “No Banco, o que eu gosto menos no meu trabalho é...", os segmentos de discurso mais representativos, identificados pelo Alceste, são apresentados pelas figuras 2, 3, 4 e 5. As palavras que compõem os segmentos e que foram emitidas com maior freqüência estão identificadas nos balões pelo sinal \#.

Em relação ao "Eixo 2 do Discurso" dos bancários sobre o "No Banco, o que eu gosto menos no meu trabalho é...", os segmentos de discurso mais representativos, identificados pelo Alceste, são apresentados pela Figura 6 .

Os resultados de natureza qualitativa complementam a base empírica para análise, interpretação e discussão.

\section{Discussão}

Globalmente, os resultados da pesquisa fornecem elementos pertinentes para aplicação dos recortes analíticos propostos com base na abordagem conceitual adotada na pesquisa. É o momento de retomar cada um deles.

\section{O discurso dos bancários: traços de cultura e cultura organizacional}

Os resultados evidenciam uma espécie de "núcleo duro" das temáticas que surgem das respostas dos bancários à questão "No Banco, o que eu gosto menos no meu trabalho é...”. Os eixos estruturadores das representações dos participantes e seus respectivos núcleos temáticos se constituem num modo de pensar emblemático dos conteúdos evocados sobre o "gostar menos no meu trabalho". Tal modo de pensar coletivo contempla duas facetas distintas: de um lado, o discurso volta-se para o ambiente organizacional e coloca em primeiro plano aspectos que estão na origem do gostar menos no trabalho (e.g., carreira e estilo de chefia); de outro, o conteúdo do pensamento coletivo aborda o modo de gestão do trabalho e suscita aspectos relativos às tarefas (e.g., trabalho repetitivo).

Nesse contexto, os resultados dão visibilidade ao sentido amplo de cultura nas acepções assinaladas por Ferreira (2004) e Motta (1997). Os eixos e núcleos temáticos são construções simbólicas, por meio de signos linguísticos, compartilhadas pelos bancários. Eles são produção e produtos simbólicos dos participantes da pesquisa e ex- 


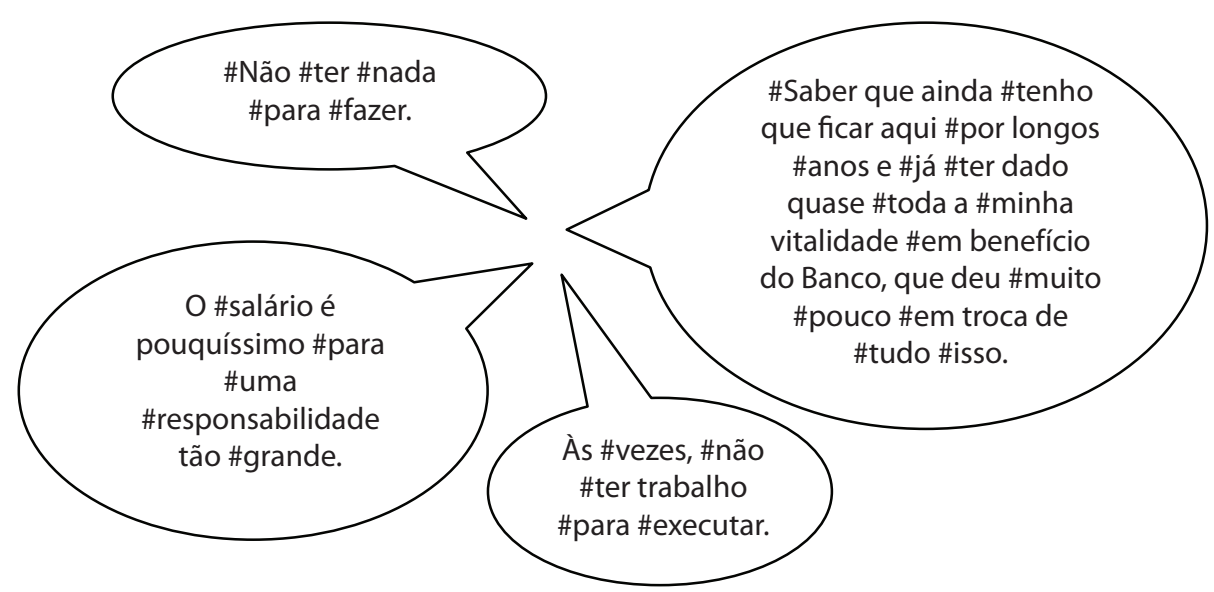

Figura 2. Segmentos de discurso representativos do núcleo temático "Ociosidade, Salário, Reciprocidade" (29,51\%).

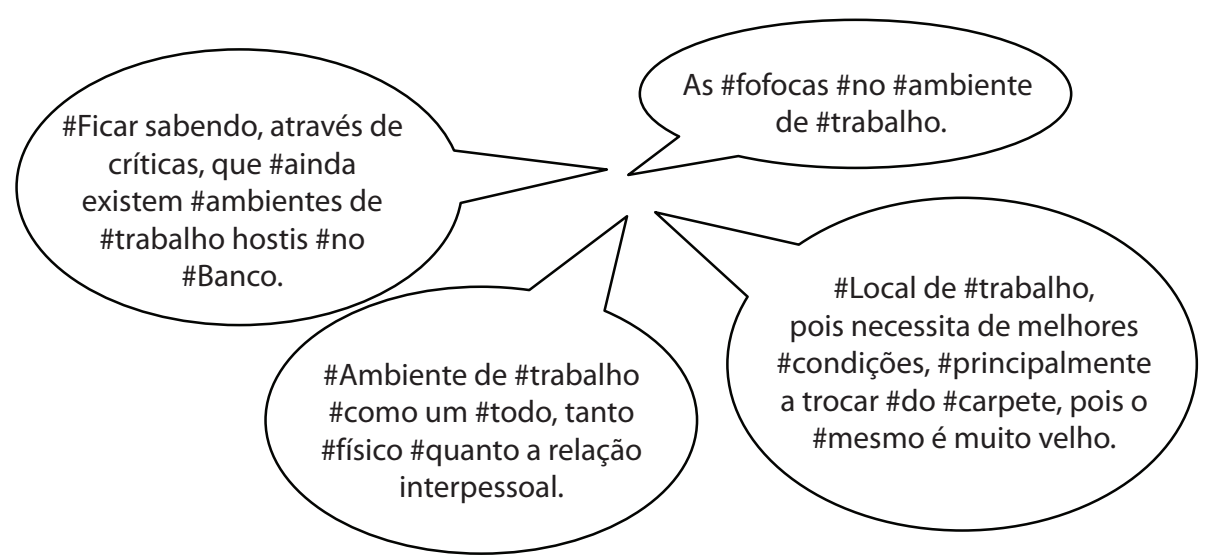

Figura 3. Segmentos de discurso representativos do núcleo temático “Hostilidade e Condições Físicas” (16,67\%).
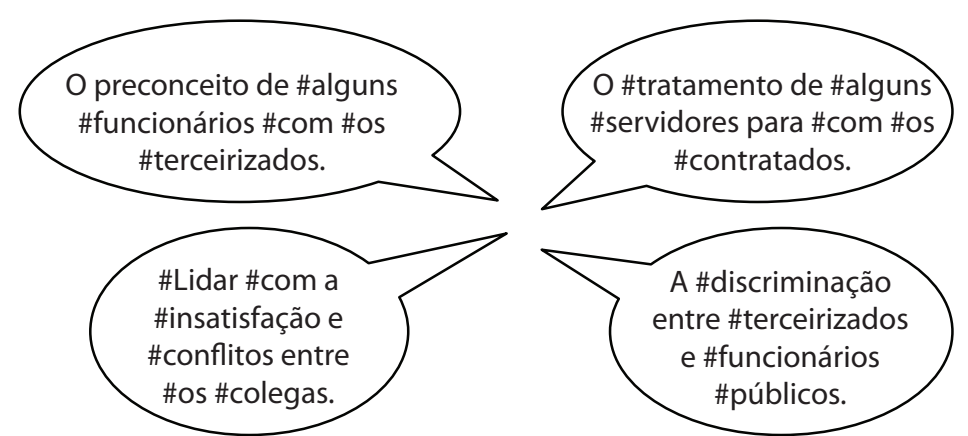

Figura 4. Segmentos de discurso representativos do núcleo temático "Discriminação para com os terceirizados" $(14,62 \%)$.

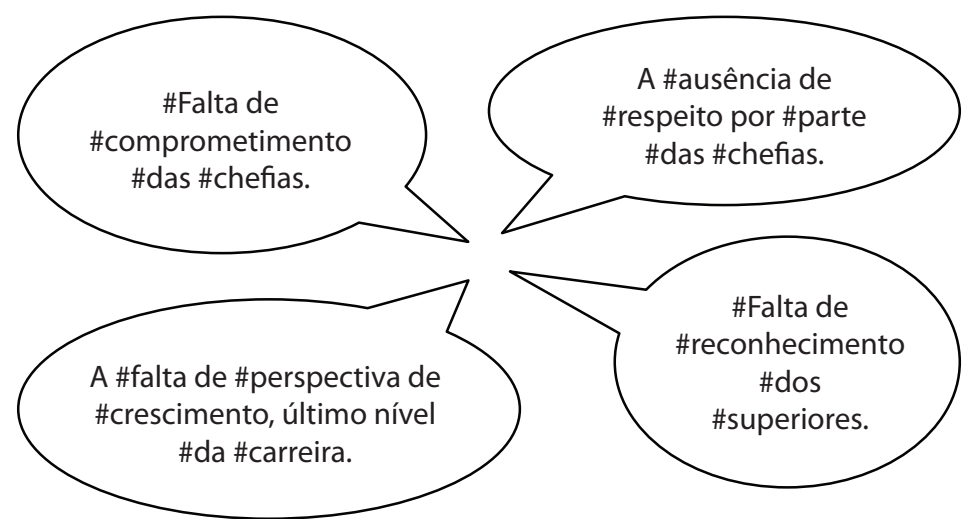

Figura 5. Segmentos de discurso representativos do núcleo temático "Carreira e Estilo de Chefia" (29,64\%). 


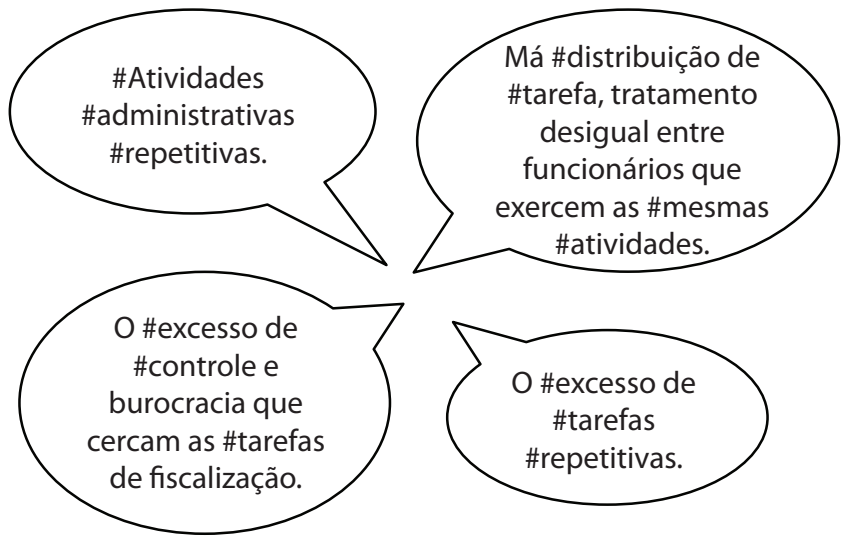

Figura 6. Segmentos de discurso representativos do núcleo temático “Trabalho Repetitivo, Controle e Divisão de Tarefas” (9,56\%).

pressam, conforme salienta Motta (1997), um universo de significações sobre as origens dos aspectos associados ao "gostar menos no trabalho", cuja linguagem particular busca dar um sentido ao mundo (contexto de trabalho) em que vivem. Nessa perspectiva, os eixos e núcleos temáticos designam, classificam, articulam e ordenam os aspectos configuradores da acepção de cultura no sentido largo da noção. Eles fornecem, portanto, uma espécie de horizonte simbólico de significações para se acessar as bases concretas do mal-estar no trabalho.

Os elementos constitutivos e característicos do discurso dos bancários permitem também identificar um perfil da cultura organizacional com base no enfoque proposto por Freitas (1997). Os eixos e núcleos temáticos identificados, certamente, nascem das relações vivenciadas pelos bancários no dia-a-dia da instituição e expressam valores (e.g., perspectiva de crescimento na carreira), normas (e.g., excesso de burocracia), significados (e.g., falta de reconhecimento dos superiores) e interpretações (e.g., carpete velho como causa de condições pouco adequadas de trabalho). O sentido que aponta o "núcleo duro" do discurso torna visível as fontes do "gostar menos no trabalho”, associandoas com aspectos do ambiente organizacional - no sentido amplo - e ao modo pelo qual é feita a gestão do trabalho (e.g., divisão de tarefas).

\section{O discurso dos bancários: os focos do mal-estar no trabalho}

Os resultados obtidos e avaliados com base nas noções de BET (Gomide Júnior \& cols., 2006a, 2006b; Siqueira \& cols., 2006; Siqueira \& Padovam, 2008) permitem identificar o "reverso da medalha”, ou seja, em que medida eles mostram elementos constitutivos e característicos do mal-estar no trabalho. Nesse sentido, a Tabela 1, apresentada a seguir, busca realizar um cotejamento dos aspectos fundantes do conceito de BET - construto psicológico multidimensional - com base nos resultados empíricos da pesquisa para delinear os focos estruturadores do mal-estar no trabalho para os bancários.

O exame mais específico (zoom in) dos resultados mostra os contornos do mal-estar no trabalho, evidenciando aspectos pertinentes, interessantes e inusitados em relação à literatura. Neste sentido, cabe destacar:

- No núcleo temático “ociosidade, salário, reciprocidade”, o mal-estar no trabalho quanto ao salário é bastante conhecido e recorrente na literatura (Silva Júnior, 2001), mas o dado relativo à ociosidade contrasta com as queixas recorrentes dos trabalhadores de estresse, fadiga e desgaste (Glina, Rocha, Batista \& Mendonça, 2001);

- No núcleo temático "hostilidade e condições de trabalho”, o mal-estar no trabalho está associado ao clima organizacional e à precariedade do suporte organizacional, confirmando resultados de outros estudos (Figueroa, Schufer, Muiños, Marro \& Coria, 2001);

- No núcleo temático “discriminação para com os terceirizados”, o mal-estar no trabalho tem origem no modo de tratamento dos trabalhadores terceirizados e sugere a existência de "dois mundos" ou dois grupos de trabalhadores bem distintos, autorizando a hipótese sobre a possível existência do fenômeno sociológico “casa grande e senzala” da obra clássica de Freire (1999);

- No núcleo temático "carreira e estilo de chefia”, o malestar no trabalho se reporta a fatores bem conhecidos na literatura, ou seja, o desejo legítimo de crescimento profissional parece obstruído e os estilos de gestão (postura e forma de tratamento) denotam tanto aspectos relativos à capacitação quanto indícios de assédio moral no trabalho (Scanfone \& Teodósio, 2004);

Tabela 1. Noção de bem-estar e focos do mal-estar no trabalho.

Bem-estar no trabalho

Satisfação no trabalho

Envolvimento com o trabalho

Comprometimento organizacional afetivo

\section{Focos do mal-estar no trabalho, conforme resultados da pesquisa}

Insatisfação proveniente do ambiente organizacional (e.g., fatores físicos, sociais e baixa perspectiva de carreira) e do modo de gestão do trabalho (e.g., distribuição desigual de tarefas e excesso de controle).

Desengajamento proveniente de tarefas repetitivas, tratamento desigual entre funcionários e relações interpessoais de trabalho conflituosas.

Descomprometimento proveniente do não reconhecimento profissional pelos superiores hierárquicos, da falta de comprometimento e postura desrespeitosa das chefias, da falta de reciprocidade do banco pelos serviços prestados. 
- No núcleo temático "trabalho repetitivo, controle e divisão de tarefas”, o mal-estar no trabalho se associa com fatores fortemente presentes nos resultados de estudos e pesquisas como repetitividade, falta de autonomia no trabalho e modelo de gestão do trabalho de viés taylor-fordista (Lacaz, 2000).

Tais resultados fornecem valiosos subsídios aos especialistas no campo das ciências do trabalho - numa perspectiva aplicada - para o planejamento, execução e avaliação no campo de "gestão com pessoas" (Oliveira \& Ferreira, 2006).

\section{O discurso dos bancários: dimensões do mal-estar no trabalho}

Finalmente, o enfoque de CPBS (Ferreira \& Mendes, 2003) permite examinar os resultados sob uma ótica taxonômica, ou seja, os distintos eixos e núcleos temáticos se constituem em fontes de dados relativos às condições de trabalho, à organização do trabalho e às relações sociais de trabalho. A Tabela 2 sumariza essa perspectiva de análise dos resultados.

Tal classificação reúne um elenco de indicadores críticos que, em sua maioria, encontram ressonância em outros achados presentes na literatura (Magalhães, 2006; Soares, 2006). Além disso, aponta para aspectos específicos sob os quais devem ser implementadas ações de mudanças para a promoção do bem-estar no trabalho.

\section{Considerações Finais}

A principal contribuição da pesquisa consistiu em fornecer uma visão panorâmica sobre a temática do mal-estar no trabalho, sob a ótica dos bancários que participaram da pesquisa. Tal visão panorâmica se fundamenta em três dimensões complementares:

- Os resultados, sob a ótica de signos linguísticos, mostram elementos característicos da produção simbólica sobre os principais aspectos associados ao "gostar menos no trabalho" - sentido amplo de cultura. Ao mesmo tempo, os eixos e núcleos temáticos identifica- dos evidenciam os traços culturais específicos de uma cultura organizacional em termos de valores, normas e interpretações que servem de "pano de fundo" para se compreender as bases concretas das representações de mal-estar no trabalho;

- Com base no enfoque de BET, os resultados fornecem elementos pertinentes para delinear os focos principais do mal-estar no trabalho - reverso da medalha - que estão associados à insatisfação, ao desengajamento e ao descomprometimento; e

- À luz do conceito de CPBS, os resultados possibilitaram gerar uma classificação específica (taxonomia), contendo os principais indicadores críticos que atuam como fontes do mal-estar no trabalho.

Em um momento histórico em que se operam metamorfoses aceleradas no mundo do trabalho, os resultados da pesquisa fornecem uma micro contribuição sobre as origens do mal-estar e seus traços culturais específicos do serviço público brasileiro em um contexto bancário. Busca-se mostrar que a tão propalada promoção do bem-estar no trabalho requer remover/atenuar as causas do mal-estar que, no caso presente, estão intimamente articuladas com o ambiente organizacional e o modelo de gestão do trabalho.

Do ponto de vista de sua aplicação, os resultados da pesquisa fornecem valiosas informações que podem servir não só de fonte para reflexões sobre a realidade organizacional estudada, mas, sobretudo, como subsídios para uma agenda de mudanças organizacionais voltadas para a promoção do bem-estar no trabalho. Nesse sentido, o diagnóstico oferece um pertinente ponto de partida aos dirigentes e gestores responsáveis por ações no campo de "gestão com pessoas".

Como toda pesquisa, esta também tem seus limites. Assim, dois aspectos merecem ser assinalados. Em primeiro lugar, apesar de muitos dos resultados encontrarem similaridade com outras pesquisas, eles não autorizam generalizações extra-muros da instituição estudada; necessita-se, assim, de novos estudos e, certamente, com um delineamento metodológico mais condizente com tal perspectiva. Em segundo lugar, os resultados mostram uma espécie de "ponta do iceberg” das causas do mal-estar no trabalho, ou seja, faz uma útil "fotografia" sobre como os participantes percebem as fontes do mal-estar, mas nada diz sobre a gênese e a dinâmica

Tabela 2. Contexto organizacional e fontes do mal-estar no trabalho.

\section{Contexto de produção de bens e serviços (Ferreira \& Mendes, 2003)}

Condições de trabalho

Organização do trabalho

Relações sociais de trabalho

\section{Fontes do mal-estar no trabalho, conforme resultados da pesquisa}

Precariedade do local de trabalho; carpete velho; falta de reciprocidade institucional; salário baixo e incompatível com as responsabilidades do cargo; falta de perspectiva de crescimento na carreira

Ociosidade; tarefas administrativas repetitivas; distribuição incorreta de tarefas; excesso de tarefas repetitivas; excesso de controle; burocracia nas tarefas de fiscalização

Críticas; relacionamento hostil; fofocas; conflitos interpessoais; discriminação para com os terceirizados; tratamento desigual entre funcionários; insatisfação dos colegas; chefias descomprometidas, com postura desrespeitosa e que não reconhecem o trabalho dos subordinados 
do objeto estudado; isto, certamente, demandaria o uso de instrumentos metodológicos complementares (e.g., entrevista semi-estruturada, observações).

Toda pesquisa também abre novas trilhas de investigação e, não raro, produz uma gama de novas perguntas que inquietam gerações de pesquisadores. No caso presente, as perguntas são muitas, mas duas já fornecem uma extensa agenda de pesquisa para o futuro: (a) como os sujeitos lidam com os fatores causadores do mal-estar para não só garantirem o bem-estar pessoal, mas também a missão e objetivos organizacionais?; e (b) em que medida o delineamento conceitual da temática 'mal-estar no trabalho' poderia facilitar o desenho metodológico e analítico em novos estudos nessa área?

Por fim, cabe assinalar que esta pesquisa alimenta - de forma pontual - o processo de reflexão sobre o sentido e o papel ontológico do trabalho, pois este deve ser sempre fonte de construção da história humana com base no prazer em fazer (homo fabiens) e não de sofrimento e mal-estar (homo economicus). No caso presente, agregar prazer ao trabalho dos bancários implica significativas mudanças no contexto organizacional bancário e no modelo de gestão do trabalho existente.

\section{Referências}

Amaral, D. J., \& Siqueira, M. M. M. (2004). Relações entre percepção da estrutura organizacional e bem-estar de profissionais de uma empresa em processo de privatização. Em Instituto Superior de Psicologia Aplicada (Org.), Actas $5^{\circ}$ Congresso Nacional de Psicologia da Saúde (pp. 671-678). Lisboa: ISPA.

Bertero, O. (1996). Cultura organizacional e instrumentalização do poder. Em M. T. L. Fleury \& R. M. Fischer (Orgs.), Cultura e poder nas organizações (pp. 29-44). São Paulo: Atlas.

Diener, E., \& Lucas, R. F. (2000). Subjective emotional wellbeing. Em M. Lewis \& J. M. Haviland (Orgs.), Handbook of emotions (pp. 325-337). New York: Guilford.

Diener, E., Scollon, S. C., \& Lucas, R. E. (2003). The involving concept of subjective well-being: The multifacated nature of happiness. Advances in Cell Aging and Gerontology, 15, 187219.

Diniz, L. S. (2006). Vivências de mal-estar e bem-estar no trabalho em central de teleatendimento governamental. Dissertação de Mestrado, Universidade de Brasília, Brasília.

Ferreira, M. C. (2004). Bem-estar: equilíbrio entre a cultura do trabalho prescrito e a cultura do trabalho real. Em Álvaro Tamayo (Org.), Cultura organizacional e saúde (pp. 181-207). São Paulo: Artmed.

Ferreira, M. C., \& Mendes, A. M. (2003). Trabalho e riscos de adoecimento: o caso de auditores-fiscais da Previdencia Social brasileira. Brasília: Ler, Pensar, Agir.

Figueroa, N. L., Schufer, M., Muiños, R., Marro, C., \& Coria, E. A. (2001). Um instrumento para a avaliação de estressores psicossociais no contexto de emprego. Psicologia: Reflexão $e$ Crítica, 14, 653-659.

Fleury, M. T. L. (1996a). O desvendar a cultura de uma organização - Uma discussão metodológica. Em M. T. L. Fleury \& R. M. Fischer (Orgs.), Cultura e poder nas organizações (pp. 15-27). São Paulo: Atlas.
Fleury, M. T. L. (1996b). O simbólico nas relações de trabalho. Em M. T. L. Fleury \& R. M. Fischer (Orgs.), Cultura e poder nas organizações (pp. 113 -127). São Paulo: Atlas.

Fleury, M. T. L., Shinyashiki, G. T., \& Stevenato, L. A. (1997). Arqueologia teórica e dilemas metodológicos dos estudos sobre cultura organizacional. Em F. P. Motta \& M. P. Caldas (Orgs.), Cultura organizacional e cultura brasileira (pp. 273-292). São Paulo: Atlas,

Freire, G. (1987). Casa grande e senzala (25 ed.). Rio de Janeiro: José Olympio.

Freitas, M. E. (1997). Cultura organizacional: o doce controle no clube dos raros. Em F. P. Motta \& M. P. Caldas, Cultura organizacional e cultura brasileira (pp. 293-304). São Paulo: Atlas.

Garay, A. (2000). Cultura organizacional. Em A. D. Cattani (Org.), Trabalho e tecnologia - dicionário crítico (pp. 48-50). Porto Alegre: UFRGS.

Glina, D. M. R., Rocha, L. E., Batista, M. L., \& Mendonça, M. G. V. (2001). Saúde mental e trabalho: uma reflexão sobre o nexo com o trabalho e o diagnóstico, com base na prática. Caderno de Saúde Pública, 17(3), 607-616.

Gomide Júnior, S., Oliveira, A. F., \& Oliveira, B. (2006a). Comportamento de civismo nas organizações: impactos do bem-estar no trabalho e da percepção de suporte organizacional [Resumo]. Em Sociedade Brasileira de Psicologia Organizacional e do Trabalho (Org.), Anais do II CBPOT. Brasília: SBPOT. Retirado em 30/07/2007, de http:/www.sbpot.org.br/iicbpot/anais.asp.

Gomide Júnior, S., Oliveira, A. F., \& Oliveira, B. (2006b). Os impactos do bem-estar subjetivo e da percepção de suporte social no trabalho sobre o bem-estar no trabalho [Resumo]. Em Sociedade Brasileira de Psicologia Organizacional e do Trabalho (Org.), Anais do II CBPOT. Brasília: SBPOT. Retirado em 30/07/2007, de http:// www.sbpot.org.br/iicbpot/anais.asp.

Hosftede, G. (1980). Culture's consequences: International differences in work related values. Berverly Hills: Sage.

Houaiss, A. (2002). Dicionário eletrônico Houaiss da língua portuguesa (versão 1.0). Rio de Janeiro: Objetiva.

Lacaz, F. A. C. (2000). Qualidade de vida no trabalho e saúde/ doença. Ciência \& Saúde Coletiva, 5(1), 151-161.

Magalhães, G. F. O. (2006). Influências do custo humano da atividade e das estratégias de mediação na qualidade de vida no trabalho de camareiras. Dissertação de Mestrado, Universidade de Brasília,Brasília.

Maslach, C., Schaufeli, W. B., \& Leiter, M.P. (2001). Job burnout. Annual Review of Psychology, 52, 397-422.

Motta, F. P. (1997). Cultura e organizações no Brasil. Em F. P. Motta \& M. P. Caldas (Orgs.), Cultura organizacional e cultura brasileira (pp. 25-37). São Paulo: Atlas.

Motta, F. P., \& Caldas, M. P. (1997). Cultura organizacional e cultura brasileira. São Paulo: Atlas.

Nascimento-Schulze, C. M., \& Camargo, B. V. (2000). Psicologia social, representações sociais e métodos. Temas de Psicologia, 8, 287-299.

Oliveira, J. S., \& Ferreira, M. C. (2006, 16 de Dezembro). A miopia gerencial e o assédio moral no trabalho. Jornal da Comunidade, p. B3, Brasília.

Reinert, M. (1990). Alceste: Une méthodologie d'analyse des données textuelles et une application. Bulletin de Méthodologie Sociologique, 28, 24-54. 
Ryan, R. M., \& Deci, E. L. (2001). On happiness and human potentials: A review of research on hedonic and eudemonic well being. Annual Review of Psychology, 52, 141-166.

Ryff, C. D. (1989). Happiness is everything, or is it? Explorations on the meaning of psychological well being. Journal of Personality and Social Psychology, 57, 1069-1081.

Scanfone, L., \& Teodósio, A.S.S. (2004). Assédio moral nas organizações: novas roupagens para uma antiga temática? Economia e Gestão, 4(7), 71-80.

Schein, E. H. (1989). Organizational culture and leadership: A dynamic view. San Francisco: Jossey Bass.

Silva Júnior, N. A. (2001). Satisfação no trabalho: um estudo entre os funcionários dos hotéis de João Pessoa. PicoUSF, 6(1), 47-57.

Siqueira, M. M. M, Padovam, V. R., Chiuzi, R.M., \& Covacs, J.M. (2006). Análise fatorial confirmatória dos modelos teóricos de bem-estar subjetivo e de bem-estar no trabalho [Resumo]. Em Sociedade Brasileira de Psicologia Organizacional e do Trabalho (Org.), Anais do II CBPOT. Brasília: SBPOT. Retirado em 30/07/2007 de http://www.sbpot.org.br/iicbpot/anais.asp.

Siqueira, M. M. M., \& Padovam, V. A. R (2008). Bases teóricas do bem-estar subjetivo, bem-estar psicológico e bem-estar no trabalho. Psicologia: Teoria e Pesquisa, 24, 201-209.
Soares, L. Q. (2006). Assédio moral no trabalho e interações socioprofissionais: "Ou você interage do jeito deles ou vai ser humilhado até não agüentar mais”. Dissertação de Mestrado, Universidade de Brasília, Brasília.

Spink, P. K. (1997). Discurso e ideologia gerencial: reflexões a partir da experiência brasileira. Em F. P. Motta \& M. P. Caldas, Cultura organizacional e cultura brasileira (pp. 305-315). São Paulo: Atlas.

Veras, V. S. (2006). Relações sociais de trabalho e custo humano da atividade: vivências de mal-estar e de bem-estar em serviço de teleatendimento governamental. Dissertação de Mestrado, Universidade de Brasília, Brasília.
Recebido em 25.01 .07

Primeira decisão editorial em 26.01.09

Versão final em 18.02.09

Aceito em 30.03.09 